is human, and an over-worked human being lacks normal power of concentration. Can it be wondered, then, that chest examinations (which demand the greatest power of concentration) often fail to reveal lesions which might otherwise have been discovered?

I am not suggesting that the G.P. should use the scheme as a means of avoiding his responsibilities, but the moral comfort I personally obtain from it has given me added confidence in myself and our profession. How much work is involved? Hardly more than what is required for filling in a milk priority form. Moreover, my patient feels he is still under my care and, in the event of an adverse report, I gradually create an air of uncertainty in him so that the blow is somewhat lightened when the Tuberculosis Officer finally breaks the bad news after clinical examination. When bad news is broken by easy stages it is at the same time possible to put forward constructive and hopeful suggestions as one goes along. This is not only kinder, but stimulates the fullest co-operation in the patient. In the event of a result proving negative, I give the patient a mental pat on the back by telling him "how courageous he was to face up to facts," and I find it is excellent propaganda because it is good for the scheme for it to be advertised that the underlying principle is one of "routine" only. But for the cost and relative shortage of material and plates, I often would feel tempted to send along one or two occasional "unlikely cases" purely for psychological reasons.

There is another aspect arising out of war conditions. The number of patients who have suddenly discovered that their chests are weak has become almost legion. Some are, of course, genuine, but there is of course a proportion whose sole object is to evade some form of national service. Without comment I tell them that an X-ray, under the scheme, would strengthen their case (if any). This either calls their bluff, or assists genuine cases, and it would seem that even genuine eases need a little assistance once in a while!

There is one important aspect of the scheme which should be stressed. It is that the Tuberculosis Officer keeps well in the background unless the patient is referred to him for clinical examination. Subsequently, much depends on the personal handling of the patient by the Tuberculosis Officer. I have met excellent clinicians who failed to arouse any co-operation in the patient because of unfortunate mannerisms. In my own districts I am happy to say that once a patient has been seen by the Tuberculosis Officer I have never the slightest difficulty in persuading either him or his relatives to attend subsequently. I attribute this to the fact that the patients are invariably treated courteously, constructively, and with due regard to the standard of intelligence they possess.

Finally, may I suggest that the most efficient way of diagnosing tuberculosis in the early stages is by a closer co-operation between the Tuberculosis Officers and the individual general practitioners? Most G.P.s are still enthusiastic enough to be exhilarated by a closer contact with constructive clinical medicine, but I need hardly tell you that most newly qualified men are "potential specialists," with a bias for a particular branch of medicine, and so lacking a sense of true proportion, while the older doctor needs an occasional fillip to prevent himself from becoming mechanical. The Tuberculosis Officer should therefore endeavour not only to make, but to maintain, contact with the general practitioners in his area.

\title{
THE FUTURE OF POST-GRADUATE EDUCATION
}

\author{
By TREVOR H. HOWELI, M.R.C.P.Ed. \\ (former Medical Tutor, British Post-graduate Medical School)
}

To-day is the era of planning in Medicine as well as in other walks of life. Almost every plan, put forward for the improvement of medical practice, includes a section on the desirability of opportunity for post-graduate study in the brave new world at which they all aim. But not one of them goes any further into the matter. Not one tries to answer the fundamental questions which arise at once. Not one asks, "What should post-graduates be taught," or "Who is suitable to carry out such teaching," or even "Where should such instruction be given, and for what periods." Before any answer can be given to these questions, much consideration is needed.

Let us first glance at undergraduate education, to see the starting-place from which we have to go. The student of medicine is taught by a number of eminent scientists, specialists, 
and consultants in medical school and hospital. These all teach him what they consider necessary, as well as a little extra which is of special interest to them personally. The very fact of their special experience, however, renders their outlook somewhat narrow and restricted. As a rule, they are not able to relate one branch of medicine or surgery to the rest, in a way helpful to the student. The final examinations make sure that he is unlikely to commit any gross blunder, and that he has seen most of the serious types of case which need hospital treatment. Subsequent house appointments will enlarge his knowledge and experience in this field, but also make him quite unconscious of the extent of his real ignorance. When the young doctor leaves hospital for general practice, he finds himself in a strange country, and "has to learn medicine all over again." Instead of clear-cut clinical pictures with plenty of physical signs, he meets single symptoms which have no very obvious causation. As for physical signs, he may examine a dozen successive patients without finding one. A month may pass without hearing a cardiac murmur, a year may pass without seeing an acute nephritic or a fresh diabetic patient. The acute abdomen, which was seen almost daily in hospital, is infrequent in practice as well as difficult to diagnose. In fact, patients come to him for treatment and relief, not particularly for diagnosis. After a while, he collects a number of chronic cases whose diagnosis is obvious, but whose treatment is difficult. Gradually therapeutics, and not diagnostics, comes to dominate his mind. Such matters as neurological anatomy, clinical pathology, and even some niceties of clinical examination grow dimmer through lack of use. A really busy doctor literally has no time to do blood counts-except after II p.m., when his figures will not be too reliable.

When a man such as this comes to attend a post-graduate course he looks forward to getting help in solving the many problems which are met in his daily round. What can be done for Mrs. Jones' asthma when she has palpitations from adrenalin? What is at the back of Mr. Smith's periodic colic? Is it worth while making investigations about Mrs. Robinson's pruritus? These are the types of questions to which he wants an answer. But at present his course usually begins with a lecture on the principles of physical examination, followed, perhaps, by a talk on the significance of cardiac murmurs. Next comes a session on the acute abdomen and ao demonstration of clinical pathology. Elementary gynaecology, common skin diseases, diabetice management, simple nervous diseases, surgical outpatients, ward demonstrations follow each other in quick succession until notebooks are full and brain whirling. At the end of a fortnight the doctor goes back to his practice with only a few grains of all that he has been taught really applicable to his everyday round.

The young specialist, on the other hand, who has done several house appointments and clinical assistantships, takes a higher examination. After this he probably gets a hospital appointment and continues to see the same types of case on which he has been taught and examined in the past, and with which he is at home. Some of his post-graduate work is likely to take the form of research, in which he will have advice and encouragement from his seniors, as well as ample facilities for the performance of pathological or other investigations. He will have few private patients at first, and the great problem will be shortage of money, not shortage of time as with the general practitioner. If he has a gift of imparting knowledge, he will probably do some coaching of students. This may lead him eventually to start post-graduate teaching, either privately or in a hospital course. The general practitioners who come to him do not seem to know very much. They have forgotten most of their anatomy, physiology and pathology. Their methods of clinical examination are often slipshod, and they have no acquaintance with medical literature except the Practitioner and some elementary text-books. ${ }^{*}$ They are full of improperly investigated cases on which they ask for his diagnosis-a most infuriating procedure. Yet they are willing to learn, industrious, and quite intelligent in private conversation. And the income from their practices makes their teacher envious. Such men must know something after several years in practice; yet they are certainly rather ignorant of medicine and surgery as the hospital physician and surgeon know these. Conversely, the latter seem to their post-graduate students to know little and teach less about the problems arising in general practice, apart from a few technical procedures which are occasionally useful.

Having thus glanced at one aspect of post-graduate work, let us now consider the organisation of teaching for qualified medical men in this country. Apart from some courses taking place in Edinburgh and Glasgow, the bulk of graduate teaching is carried on in London. A

* (How much better would they be if only they read the P.G.M.J.!-Ed.) 
number of individuals and institutions play a part in this, but no two of them co-operate with one another to any degree. There are a number of private teachers who coach for examinations of one sort or another, a couple of correspondence colleges who do similar work, two hospitals, and finally the FELLOWSHIP OF MEDICINE. The last three bodies are the only ones of great interest to the general practitioner, even if he is thinking of a higher qualification, since they alone can provide him with clinical material. One of the hospitals, The Prince of Wales, Tottenham, welcomes medical men to rounds and outpatient clinics, but has not recently provided much organised teaching. The other, the British Post-graduate Medical School at Hammersmith Hospital, was specially created for organised teaching of qualified medical men and women. The teaching here is of a high standard, suitable for candidates who propose to sit for higher qualifications. Yet, in the opinion of many students, not enough attention is given to the needs of the general practitioner, and the specialities available are not comprehensive enough. These lacunae are not closed by co-operation with other institutions as might be expected. Again, the embryo consultant is best catered for.

It is not necessary in this JourNal to dilate on the good work carried on by the Fellowship of Medicine in arranging courses. A point which needs emphasis, however, is that the secretary of the Fellowship can, and does give to post-graduates very full details of all courses taking place in London, as well as sound advice about those which are likely to be most suitable in a particular case. So many students, without such guidance, spend all their available time in wandering from one course to another and from one clinic to another before they find what they really need.

Now let us consider what is required for future post-graduate instruction in London. First, there should be a central bureau, which could give details of all courses and clinics to the prospective student. Apart from the clerical staff, this should have medical advisers, both specialists and men with experience in general practice, who could give advice to the student and receive criticism from him. Such criticism could be passed on to the teachers and would improve their clinics and lectures considerably. Next, there could be some co-ordination of the various classes and courses in the different hospitals, so that the whole field could be covered without clashes and repetition. Thirdly, since teaching for higher examinations is well represented in different classes, more general practitioner features should be introduced. This can only be done by men with a knowledge of general practice. Such things as demonstrations of practical technique in, say, injection therapy would be-most helpful. Even a talk on how to make use of medical literature, to solve the problems which arise in practice, might be of value. The teaching of physio-therapy is long overdue, and short simple courses in diseases of the ear, nose and throat, or rectum, etc., might also be of great value if conducted on the right lines. It must never be forgotten that the majority of post-graduates are general practitioners wishing to improve their knowledge: not future specialists interested in rarities or abstruse theory. This applies in particular to refresher courses, which are often too academic.

Finally, there is no reason why London should be the only large post-graduate centre in the country. Other medical schools at Oxford, Leeds, Manchester, and similar places have both the material and the teachers necessary to give courses. Such arrangements would be of the utmost benefit to the whole profession throughout the country and raise medical standards everywhere. Let us hope that the future will see some of these improvements adopted and post-graduate study become a recognised practice for every doctor.

\section{RUTHIN CASTLE, NORTH WALES}

A Clinic for the diagnosis and treatment of Internal Diseases (except Mental or Infectious Diseases). The Clinic is provided with a staff of doctors, technicians and nurses.

The surroundings are beautiful. , The climate is mild. There is central heating throughout. The annual rainfall is $\mathbf{3 0 . 5}$ inches, that is, less than the average for England.

The inclusive fees are from 15 guineas a week, according to the room occupied; rooms with bathroom are from 21 guineas. An examination and consultation fee of 15 guineas is charged on the first visit only. doctor.

SPECIAL FEES FOR INVESTIGATION ONLY - 30 GUINEAS, including stay up to 10 days and report to 